\title{
A Framework for Studying Institutional Output and Its Alignment, Causes and Consequences
}

Exploring how the G20, OECD and IMF addressed fossil fuel subsidies and climate finance through the lens of economisation requires an analytical framework studying not only how the institutions addressed the issues, but also the causes and consequences of their doing so as well as their alignment. In this context, it is useful to draw on David Easton's (1965, chapter 22) distinction between the output and outcome of policy systems. ${ }^{1}$ Adapted to the study of international institutions, output concerns what the institutions $d o$, specifically the regulations, policy instruments, compliance mechanisms and so forth they produce (Gutner and Thompson, 2010; Young, 2001). The outcome concerns the consequences of the output in terms of changes in actor behaviour (Easton, 1965; Young, 2001). Besides output and outcome, the book also studies how the output of international institutions is aligned (degree of conflict or synergy) as well as the factors that have shaped the output. Studying the institutions' economisation of climate finance and fossil fuel subsidy reform requires studying their output to identify precisely how they have addressed the two issues as economic ones. As discussed in Chapter 1, economisation consists of two dimensions: (1) the economic institution (or actor) addressing the issue and (2) how it has addressed it, here operationalised as the institution's output.

The framework consists of different elements intended to study causes, output, alignment and outcome respectively. Within this framework, certain concepts appear in several of the steps, namely ideas (including normative and cognitive ones) and incentive structures (see Table 2.1), and constitute central themes of the book. Others, such as entrepreneurs or agenda-setting, appear in only some of the stages. Given the focus on economisation and the economic character of the institutions, the book pays particular attention to how factors pertaining to this character (e.g. the economic training of their officials) have shaped how they

\footnotetext{
${ }^{1}$ A common third dimension, the impact of policy output on the problem it was intended to address (e.g. the effects on climate change), has not been included here, as it is too difficult to isolate the effects of the institutions on these problems. On the difficulties in studying the impact of institutions, see Szulecki et al. (2011) and Tallberg et al. (2016).
} 
Table 2.1 Analytical framework

\begin{tabular}{|c|c|c|c|c|}
\hline & Output & $\begin{array}{l}\text { Alignment (syner- } \\
\text { gistic, conflictive, } \\
\text { cooperative) }\end{array}$ & Causes & $\begin{array}{l}\text { Consequences } \\
\text { (international and } \\
\text { domestic) }\end{array}$ \\
\hline $\begin{array}{l}\text { Cognitive } \\
\text { (ideas) }\end{array}$ & $\begin{array}{l}\text { Cognitive ideas } \\
\text { (e.g. definitions, } \\
\text { causal claims) }\end{array}$ & $\begin{array}{l}\text { Interpretation of } \\
\text { cognitive ideas }\end{array}$ & $\begin{array}{l}\text { Institutional world- } \\
\text { views (cognitive } \\
\text { aspects) }\end{array}$ & $\begin{array}{l}\text { Changes to cogni- } \\
\text { tive ideas (includ- } \\
\text { ing learning) }\end{array}$ \\
\hline $\begin{array}{l}\text { Normative } \\
\text { (ideas) }\end{array}$ & $\begin{array}{l}\text { Norms, normative } \\
\text { ideas }\end{array}$ & $\begin{array}{l}\text { Interpretation of } \\
\text { norms }\end{array}$ & $\begin{array}{l}\text { Institutional world- } \\
\text { views (normative } \\
\text { aspects) }\end{array}$ & $\begin{array}{l}\text { Normative change } \\
\text { (including norm } \\
\text { diffusion) }\end{array}$ \\
\hline $\begin{array}{l}\text { Incentive } \\
\text { structures }\end{array}$ & $\begin{array}{l}\text { Commitments, } \\
\text { conditionalities }\end{array}$ & $\begin{array}{l}\text { Incentives (direc- } \\
\text { tion of) }\end{array}$ & $\begin{array}{l}\text { Membership circle, } \\
\text { degree of auton- } \\
\text { omy from mem- } \\
\text { ber states }\end{array}$ & $\begin{array}{l}\text { Commitments, } \\
\text { conditionalities }\end{array}$ \\
\hline Others & & $\begin{array}{l}\text { Types of output } \\
\text { Actors targeted }\end{array}$ & $\begin{array}{l}\text { Entrepreneurs } \\
\text { Interaction with } \\
\quad \text { other institutions }\end{array}$ & Agenda-setting \\
\hline
\end{tabular}

addressed climate finance and fossil fuel subsidies, as well as the consequences of the economisation (e.g. inducing finance ministries to address fossil fuel subsidies). The similar concepts appearing at different steps (e.g. cognitive ideas) are closely interrelated. As an illustrative example, the cognitive aspects of the institutional worldview may play a bigger role than other factors in shaping cognitive output such as causal claims, which again may potentially play a more important role than other factors in changing cognitive ideas in other institutions and countries, thus constituting a cognitive pathway with several steps.

\subsection{Institutional Output: What Is It They Do?}

International institutions produce different kinds of output, such as legally binding agreements, expert reports and the provision of venues for informal networking and learning. Importantly, I focus on all kinds of actions that an institution undertakes that are directed at its external environment (i.e. not those concerning its internal dynamics such as changed procedures; see Knill and Bauer, 2016). Before turning to cognitive, normative and incentive-oriented aspects of institutional output, I discuss the different types of formal and informal output.

I divide the formal output targeting the external environment into four categories. The first is the regulatory output that promotes or prohibits specific actions, including the setting of commitments (both legally binding and soft law), recommendations and criticisms of specific actions (Tallberg et al., 2016). The second is 
the declarative output that asserts a joint position of the institution, for example common goals (Tallberg et al., 2016). It may de facto be difficult to distinguish between regulatory and declarative output, as declarative statements may also limit member states' possibilities of undertaking specific actions. The third is the knowledge output that consists of the creation and distribution of knowledge through publications, including data and analyses (Barnett and Finnemore, 2004), for example of the landscape of climate finance. The fourth is distributive output that reallocates resources, in the shape of financial and technical resources (e.g. for capacity-building), sanctions or punishments, and conditionalities for enjoying particular benefits, for example IMF conditionalities for receiving IMF loans (Tallberg et al., 2016). The informal output includes informal consultations (e.g. between representatives of the institutions and a country government), low-key support for policymaking (e.g. advice) and workshops and seminars providing a venue for the dissemination of knowledge and interaction between actors. In this way, the workshops and seminars allow for learning and socialisation.

It makes sense to focus on three aspects of their output, namely the cognitive, normative and incentive-based dimensions. ${ }^{2}$ These three dimensions can be found in most of the aforementioned outputs, for instance do all of them involve some kind of cognitive aspect in terms of defining what is important. While the classification of the output according to the typology outlined earlier is important for understanding their respective roles and comparing them, focusing on these three dimensions is crucial for understanding economisation. Specifically, the cognitive and normative dimensions concern (inter alia) how and to which degree an issue is framed as an economic issue (the second aspect of economisation), but can also involve other kinds of framings, for instance in terms of equity. Incentives do not concern economisation as directly as the other two dimensions but understanding the output and outcome of the institutions requires studying the incentive-based dimension of this output as well as the cognitive and normative dimensions.

The distinction between cognitive and normative aspects draws on the distinction between cognitive ideas regarding what something is or how to understand a given issue and normative ideas regarding 'what is good or bad' about 'what is', good and bad understood in terms of 'what one ought to do' (Schmidt, 2008). In terms of economisation, this may play out in terms of framing climate change as an externality or a market failure, a framing that includes the cognitive idea that climate change constitutes a market failure and the normative idea that this market failure should be corrected to create a long-term optimal outcome (see Jacobs, 1997; Katz-Rosene and Paterson, 2018; Skovgaard, 2012). In practice, normative

\footnotetext{
${ }^{2}$ For the sake of simplicity, these three dimensions will also be referred to as cognitive, normative and incentive-based output respectively.
} 
and cognitive ideas are often closely intertwined, for example framing a stream of revenue as climate finance leads to the conclusion that providing such revenue is appropriate. Yet, I argue that it makes sense to distinguish between them for heuristic reasons: comparing the output between the three institutions and the two areas in question provides more analytically useful results if you are able to identify to what degree the output differs regarding normative and cognitive ideas. Importantly, mainstream economics rarely determines exactly how ideas firmly established in the discipline should be applied, and hence diverging applications of ideas rooted in this discipline (even within the same paradigm such as neoclassical environmental economics) are possible.

The cognitive dimension covers the definition of what issues are, in this case climate finance and fossil fuel subsidies. More specifically, the cognitive dimension of the institutional output generally speaking refers to ideas regarding causal relations (e.g. ' $X$ causes $Y^{\prime}$ ') as well as how empirical phenomena should be defined and what is important about them (Sabatier and Weible, 2014; Schmidt, 2008). For instance, cognitive ideas regarding fossil fuel subsidies or climate finance may concern how they should be defined, what their consequences are, how they can be reformed or scaled up and so forth. Regarding causal relations, the cognitive dimension concern ideas regarding the causes of a given policy issue and the consequences of the policies addressing these issues (Campbell, 1998). Such causal ideas may concern how to best promote fossil fuel subsidy reform or use climate finance. Regarding the definition of the phenomena, both issues have been characterised by intense disputes over their definitions, that is whether a given policy can be characterised as a fossil fuel subsidy (Skovgaard, 2017a; see Chapter 4 for more details) or a financial flow as climate finance (Roberts and Weikmans, 2017; Skovgaard, 2017b; see Chapter 9 for more details). The definitional aspect is important not only in terms of which policies or financial flows fall under the definition, but also which aspects of the issue (fossil fuel subsidies or climate finance) are important, for example if they are framed as economic issues rather than environmental or development ones. Often, the definition of the problem shapes causal ideas about the solutions that are logical to use (Schön and Rein, 1994). On a closely related note, the cognitive dimension also concerns the kinds of data that are relevant for understanding the issue, for example whether it is best measured in quantified, monetary terms, specifically in terms of economic costs or benefits (Jacobs, 1997). The production of knowledge is a key type of formal institutional output (as discussed in the beginning of this section), and such knowledge production has a strong cognitive dimension in defining what is important about an issue and how it can be measured, for example the size of fossil fuel subsidies and climate finance flows. 
The normative dimension refers to how the institutions define the key normative issues that characterise the politics of fossil fuel subsidy reform and climate finance. Normative ideas refer to normative ideas about 'what one ought to do' (Schmidt, 2008), including norms understood as intersubjective standards of appropriate behaviour (Finnemore and Sikkink, 1998; March and Olsen, 1989) as well as more fundamental normative ideas about what is right and desirable. Regarding the former, a relevant example of a norm is the emerging norm of fossil fuel subsidy reform, which defines fossil fuel subsidies as environmentally damaging and as something that should be phased out (Van de Graaf and Blondeel, 2018). More specifically, concerning international economic institutions, Susan Park and Antje Vetterlein (2010b) define policy norms as shared expectations for all relevant actors within a given community about what constitutes appropriate behaviour, which is encapsulated in policy output. Regarding the latter, relevant fundamental normative ideas include the idea that (policy) objectives should be defined in terms of optimising economic output (Cole, 2008; Jacobs, 1997; Skovgaard, 2017b). The exact meaning and application of normative ideas have been highly contested at the international level, as has been the case with the norm of fossil fuel subsidy reform, which has been characterised by disagreement between international economic institutions regarding to what extent many countries subsidise fossil fuels (Skovgaard, 2018; Van de Graaf and Blondeel, 2018). While all output of the institutions has or may have a normative dimension, the normative dimensions are particularly relevant when they act as norm entrepreneurs (Finnemore and Sikkink, 1998).

The third dimension of institutional output consists of incentives, referring to measures that aim to change the incentive structures facing actors. Unlike the ideational dimension, incentives do not alter the ideas and knowledge held by actors or which ideas are considered appropriate or authoritative but aim to change actors' behaviour by altering the costs and benefits associated with particular actions. While normative ideas may affect actors' preferences and hence how they react to incentives, the incentive-based dimension of output concerns incentive structures that influence actors without changing their preferences. Thus, while actors may change their preferences, these preferences tend to be constant and determine how the actors respond to incentive structures. More specifically, while the ideational aspects concern the shape economisation takes in terms of how climate finance or fossil fuel subsidies are framed as economic issues (cognitively and normatively), the incentives concern how economisation translates into concrete incentives for and against particular actions. Incentive-based output has been the focus of liberal institutionalist literature, which argues that international institutions are created to provide incentives for cooperation through punishing non- 
cooperation and rewarding cooperation, for example by providing transparency regarding whether a state cooperates or not, allowing for punishment from other states or an International Organisation (IO) (Keohane, 1984, 1989). The incentive-based output of the institutions may take the shape of regulatory agreements among member states or between the institution and a state, or of distributive output such as the provision of support (both being formal types of output). The former agreements include inter alia commitments between states (e.g. to undertake fossil fuel subsidy reform or provide climate finance), the violation of which may result in sanctions or reputational costs that would reduce the state's credibility when future commitments (in this field or in others) are to be negotiated (Smith and Urpelainen, 2017). Whereas sanctions are generally explicitly defined as a response of the institution to particular actions, reputational costs operate through states (including but not limited to member states) having less faith in the state violating the commitment. Incentives also include distributional output in the shape of conditionalities (e.g. cessation of IMF loans if countries do not reform fossil fuel subsidies; see also Schimmelfennig et al., 2005; Vreeland, 2007) as well as material support (e.g. finance or expertise) for particular actions. Finally, beyond regulatory and distributive output, the incentive-based output also includes output that allows for states to signal the credibility of their offers or commitments, or to gain more information about the offers or commitments of other states, for example through informal discussions or the provision of data (on the role of commitments and information in international negotiations; see Underdal, 1983).

\subsection{How Institutions Align}

After identifying the institutional output of the different institutions, the next step is to explore how their output is aligned. While the direct effects of one institution's output on another institution (e.g. one institution placing a commitment on another) will be studied in the section on the consequences of institutional output, in this section, I focus on the extent to which their output is synergistic, co-existing or conflictive (Biermann et al., 2009a; Zelli et al., 2020). In other words, the different kinds of output may support or undermine each other, or they may be directed at different issues or governance functions in a non-interacting way that neither supports nor undermines the output of other institutions, for example because they occupy different niches (Abbott et al., 2016).

First, regarding the cognitive ideas, if the different institutions use different sets of such ideas to describe the same empirical phenomenon, it may constitute a conflictive relationship (March and Olsen, 1989; Schön and Rein, 1994). Such conflict may concern what is important about the issue or causal relationships in the shape of divergence regarding the causes of or solutions to a particular problem. 
The institutions may also differ regarding the definition of fossil fuel subsidies and climate finance, and hence also whether a given policy constitutes a fossil fuel subsidy or a financial flow of climate finance. Beyond conflict, diverging outputs may also lead to the outputs being of little relevance to each other and creating confusion among audiences (where similar audiences are targeted) regarding what is important as well as information overload (Skovgaard and Canavan, 2020; Zelli et al., 2020). As regards knowledge that is based on similar or closely related cognitive ideas, the output from the institutions is more likely to be synergistic, for example the IMF building on OECD data on climate finance streams when producing its own analysis of climate finance.

Second, normative output may be more or less conflictive or synergetic, the former in terms of outright conflicting norms but also in terms of differing interpretations of the same norm. Although conflict between the core norms of the institutions (Biermann et al., 2009a) is unlikely given that these core norms are based on very similar economic paradigms (Bernstein, 2001; Chwieroth, 2008; Lehtonen, 2007; Slaughter, 2017), institutions' interpretations of climate-related norms as well as fundamental normative ideas may differ. The contestation over norms may concern their application to concrete situations (Wiener, 2004), as even relatively minor differences in the interpretation may lead to widely different applications of the norm, for example whether a country's fossil fuel subsidies are inefficient and hence should be reformed or not (Van de Graaf and Blondeel, 2018). More fundamentally, contestation over normative ideas may concern their general appropriateness and validity, as well as how they should be prioritised visà-vis each other, for example how efficiency (also known as cost-effectiveness) should be prioritised vis-à-vis equity (see Chapter 9).

Thus, while the institutions' economic core norms pull in the direction of synergy on some fundamental issues (e.g. economic growth and stability being key objectives), there is ample scope for synergy and co-existence as well as conflict regarding several normative ideas and the interpretation of norms. Importantly, synergistic relationships may strengthen particular interpretations of norms or normative ideas, for example if several institutions promote the same interpretation of a given norm. Finally, there may be an intentional or unintentional division of labour, in which certain institutions promote specific norms.

Third, in terms of incentives, the key issue is whether these incentives pull in the same or diverging, even opposite, directions. If, for instance, one institution provides support for one kind of action, while another punishes such behaviour, the incentives are conflicting (Gehring and Oberthur, 2009). Synergistic relations are equally possible, for example in the shape of one institution providing (material) support for actions that will help a state to meet its obligations under a commitment 
produced by another institution. Beyond providing incentives pulling in similar or opposite directions, there is also the possibility that the incentives provided by different institutions crowd each other out, for example by providing such a multitude of different incentives that it is not possible for the actors targeted to respond to all of them (Abbott et al., 2016; Eberlein et al., 2014).

Fourth, it is worthwhile studying how the institutions align in terms of their types of output or governance functions. It is relevant whether all institutions focus on the same kind of output, for example setting commitments or producing knowledge, or if there is an explicit or implicit division of labour, so that one may focus mainly on knowledge production, a second on defining norms and a third on distributive output providing financial incentives (Gehring and Faude, 2014; Zürn and Faude, 2013). While each of the institutions generally provide several types of output, they may differ as to which one is the main type.

Fifth, and finally, it may matter which actors are addressed by the output of the institutions. The three institutions differ concerning the states that are their members: the G20's membership covers twenty of the largest (developed and emerging) economies, the OECD all developed countries and the IMF most countries in the world. Furthermore, the institutions also differ to some degree regarding the government institutions they interact with: while the IMF and the G20 interact mainly with finance ministries and central banks (and in the case of the G20 also the offices of heads of state and government), the OECD interacts with many different ministries (Kirton and Kokotsis, 2015; Ruffing, 2010; Vreeland, 2007). All things considered, there are significant overlaps in terms of the actors they address, but there is also a range of actors that are addressed only by one of the institutions. An overlap may increase the likelihood of conflicting institutional output, as different institutions may promote diverging norms, knowledge or incentives to the same states (Zelli et al., 2020). This risk is particularly pertinent if they address different ministries within the same country, for example if the OECD promotes one interpretation of a norm to development or energy ministries and the IMF a different interpretation of the same norm to the finance ministry. Institutions addressing different states with differing output risk creating conflictive relationships among countries as well as institutions.

\subsection{Causes of International Economic Institutions' Output and Alignment}

The next step is to identify the factors that shape the output and the alignment of the institutions, both in terms of inducing an institution to address fossil fuel subsidies and climate finance in the first place and of shaping how they address them. 
Importantly, inducing the institutions to address the issues concerns the first aspect (that economic institutions address the issue) and how they address the issue concerns the second aspect of economisation (that they address the issue as an economic one). Thus, although these two aspects are closely related (as discussed in Chapter 1), one factor may be more relevant for the first aspect than the second and vice versa. The factors that shape the output of the institutions are also important for shaping their alignment; that is, if similar factors shape their output, the alignment will be synergistic. Hence, I first outline how the factors may shape the output of an individual institution, and subsequently discuss their relevance to institutional alignment. I draw on strands of international relations literature that focuses mainly on institutions as actors in their own right, independent of state behaviour (Barnett and Finnemore, 2004; Nielson and Tierney, 2003; Park and Vetterlein, 2010a) as well as literature on international institutions and their interaction (Oberthür and Stokke, 2011; Zelli and Asselt, 2013). Given that two of the institutions (the IMF and the OECD) are IOs, the first strand of literature is highly relevant to them but less so (and in a different way) to the G20.

Regarding the IO strand, Biermann et al. (2009b) distinguish among three kinds of influences on IOs: problem structure, extra-organisational (mainly member states) and the organisation itself. The two problem structures of the two policy issues (fossil fuel subsidies and climate finance) are constant between the institutions analysed here, thus allowing for a study of the effect of problem structure only when comparing the institutions' handling of the two issues (in the concluding Chapter 14). Here, problem structure refers to the position of the issues in policy spheres (in this case economic and environmental), their costs and benefits (here especially fiscal costs), their degree of international contestation (especially NorthSouth contestation) and how entrenched state preferences regarding the issues are (Jinnah, 2015; Weiss and Jacobson, 1999).

Yet, extra- and intra-organisational factors vary between the institutions, allowing for a comparison of the three institutions' handling of each issue. Intraorganisational influences explain the role of IOs in terms of their organisational culture and policy entrepreneurs within the bureaucracies (Barnett and Finnemore, 2004; Park and Vetterlein, 2010b). Extra-organisational influences mainly explain the role of IOs in terms of their status as agents contracted by principals (the member states) to perform a function that will benefit the principals (Hawkins et al., 2006; Nielson and Tierney, 2003). I argue that although the G20 does not have a bureaucracy as such, it is possible to speak about intra-institutional factors also in its case, namely policy entrepreneurs with an institutionalised role (e.g. G20 presidents and chairs of working groups) and the worldview inherent to the G20 (see also discussion in Chapter 1 of the relationship between IOs and institutions). 
I organise the various causal factors from the literature into four categories. These categories are the worldview of the institution ${ }^{3}$ (intra-institutional), policy entrepreneurs operating within the institution (intra-institutional), relations with member states (extra-institutional) and interaction with other institutions (extrainstitutional). While these institutions vary significantly in terms of relations with member states, they vary less in terms of the other factors (see the discussion of case selection in Chapter 1). In Chapter 3, the three institutions' worldviews, relations with member states and interaction with other institutions are discussed in more detail.

The institutional worldview refers to normative as well as cognitive ideas inherent to the individual institutions and together constitute the worldviews that shape how they perceive and address policy issues (e.g. the IMF's worldview rooted in neoclassical economics leading it to define the non-pricing of externalities as a subsidy). This worldview may play an important role in shaping how the institutions address fossil fuel subsidies and climate finance, but cannot directly induce them to address it, only constitute a contextual factor for other factors inducing the institutions to address the issues. The sociological institutionalist IO literature focuses on the worldviews of IO bureaucracies (Barnett and Finnemore, 2004; Park and Vetterlein, 2010b), and draws on sociological and historical institutionalist (Hall and Taylor, 1996; March and Olsen, 1989) and cognition-oriented bureaucratic politics literature (Allison and Zelikow, 1999; Drezner, 2000) to argue that such worldviews are inherent to the bureaucratic cultures of the IO bureaucracies. In the words of Graham Allison and Philip Zelikow (1999), 'where you stand depend on where you sit'. These worldviews are inherent to the institutions and shape how the actors within the institutions perceive policy issues, including what is problematic about them, their causes and how they can and should be addressed (Bacchi, 2009). Thus, the worldview encompasses both cognitive and normative ideas, which, as mentioned previously, are often closely linked, since the framing of the situation defines which norms are salient, which actions are logical and what the consequences of the different actions will be (Kratochwil, 1989).

In the case of bureaucracies, the worldviews are more institutionalised than in a forum such as the G20. Regarding such international bureaucracies, their organisational culture is closely tied to the training (particularly educational background) of the officials - in the case of the international economic institutions their training as economists (Chwieroth, 2010; Kanbur, 2001). Training and worldview are hard to disentangle in practice, not only because they tend to pull in the same direction, but also because organisations characterised by a particular

\footnotetext{
3 I use the term 'institutional worldview' or just 'worldview' rather than 'organisational culture' because it does not presuppose a bureaucratic organisation (relevant in the case of the G20), and because it focuses specifically on the perception of issues, unlike culture, which covers a broader range of organisational characteristics.
} 
worldview tend to recruit staff with an educational background (from specific disciplines such as economics and even particular universities) that corresponds with this worldview, in this way reproducing the worldview (DiMaggio and Powell, 1983). The worldviews of the institutions are not entirely unitary, but often differ in some respects between different sections and divisions of a bureaucracy (Kaarbo, 1998). Thus, a bureaucracy may be characterised by a shared set of core normative and cognitive ideas, for example that optimising economic value is the main objective and that market logic constitutes an optimal way of achieving it, but may differ among sections regarding secondary beliefs or ideas, for example the relationship between economic value and other objectives (on the relationship between different levels of beliefs or ideas, see Jenkins-Smith et al., 2014). Importantly, the worldview operates on a much broader scale than the cognitive and normative output, that is, the worldview concerns ideas on a conceptual level potentially applicable across a broad range of cases, whereas cognitive and normative output concerns the ideas applied to a concrete situation.

Regarding the worldviews of the three institutions (see also Chapter 3), the OECD's approach to environmental issues has often been characterised in terms of the paradigm of 'liberal environmentalism' stressing economic instruments and compatibility between economic growth and environmental protection (Bernstein, 2001). The IMF is arguably more directly influenced by neoclassical economics than the OECD (Chwieroth, 2008; Howarth and Sadeh, 2011). Finally, the G20 does not have a bureaucracy, but relies on the G20 Presidency as secretariat. Even if the worldviews are less institutionalised in a forum such as the G20, the frequent interaction between actors may establish a shared worldview or at least perspective on an issue, especially if the participants come from bureaucracies with similar worldviews (e.g. finance ministries) and share educational background (DiMaggio and Powell, 1983). A forum for experts within the G20 set-up may develop into an epistemic community sharing normative and causal beliefs as well as a common policy enterprise (Haas, 1992). Even if it does not fully develop into an epistemic community, socialisation processes may be present, in which case the worldviews of the participants start to converge around a set of normative and causal beliefs (Johnston, 2001).

The term policy entrepreneurs refers to individuals within the institutions (especially their bureaucracies) as well as to collective actors, who may induce the institutions to address an issue or promote particular ways of addressing it (e.g. treating climate finance as a kind of development aid). Policy entrepreneurs are understood as actors promoting significant policy change (Mintrom and Norman, 2009). Their activities include framing policy problems, advocating new ideas and policy proposals, specifying policy alternatives, mobilising public opinion and 
setting the decision-making agenda (Kingdon, 2003; Roberts and King, 1991). As regards new issues, policy entrepreneurs promote them by framing them in ways that lead to particular policy responses (Chwieroth, 2008), and are less constrained in their framings than in the case of established issues. The lesser constraint is due to new issues having a lower degree of precedence (prior action on the issue) and determinacy (agreement on how an issue shall be understood and which ideas apply; see Jordan and Huitema, 2014; Rhinard, 2010; Skovgaard, 2015). They also promote new issues by moving them up the agenda of the institution they operate within as well as other institutions and organisations (Bakir, 2009; Kingdon, 2003). The policy entrepreneurs have to operate within the worldviews of the institutions and frame issues in ways that resonate with these worldviews. They also have to operate within the constraints and opportunities constituted by the resources available and their mandates. In the case of entrepreneurs from IO bureaucracies, these constraints and opportunities originate from the bureaucracy and the relationship with the member states (see later in this section). In the case of the G20, the constraints and opportunities stem from the set-up of the G20, with a Presidency chairing meetings and expert groups reporting to ministerial meetings, as well as constraints and opportunities within the state that the policy entrepreneur works for, for example, domestic decision-making procedures. Policy entrepreneurs are distinguished from norm entrepreneurs in that they work to change policy rather than promoting a specific norm (see Finnemore and Sikkink, 1998 on norm entrepreneurs), yet de facto several of the policy entrepreneurs studied here may also be defined as norm entrepreneurs.

Relations with member states is a term that covers which states are members of the institutions, how the member state representatives arrive at decisions (voting or consensus), the ministries that represent the states vis-à-vis the institutions and the degree of autonomy of the institutions' bureaucracy vis-à-vis the member states. It is relatively straightforward for a member state to induce institutions to address an issue (unless other member states veto such efforts, as Saudi Arabia did in the case of fossil fuel subsidies prior to 2009). Yet their ability to prevent the institution from addressing an issue and shape how the institution addresses it depends on its autonomy (discussed later in this section). Membership in terms of which states are members is relevant, since the aggregate state preferences and power constitute one factor shaping the institutional output (Zürn and Faude, 2013). The G20 covers twenty of the world's largest developed and emerging economies, OECD covers only developed countries and while the IMF covers most countries, its voting rules grant the major developed countries a position close to a combined veto power, with the United States according to some scholars having an influence beyond its share of votes (Stone, 2008). This is 
because the IMF arrives at decisions through voting, with voting rights reflecting a country's share of the global economy, while the G20 and the OECD member states arrive at decisions through consensus. The question of which ministries represent the member state may also matter (Raustiala and Victor, 2004; Skovgaard, 2012), since different ministries are characterised by different objectives and worldviews (Allison and Zelikow, 1999). For instance, finance ministries promote fiscal balances and growth and see the world through an economic lens (Seabrooke, 2011; Skovgaard, 2017b; Wildavsky, 1986), and environment ministries promote environmental protection (Weale et al., 1996).

Regarding autonomy, principal-agent theory (relevant only to IO bureaucracies) focuses on the role of these bureaucracies in terms of their status as agents contracted by the principal (the member states) to perform a function that will benefit the principal, and on the IO's degree of autonomy from principals (Hawkins et al., 2006; Nielson and Tierney, 2003). The member states constitute one collective principal that delegates the task of addressing an issue to the agent (the IO). The more autonomy the agent has, the more it can act independently of the principal and produce output that differs, even contradicts, the preferences of key member states or even the principal as a whole.

The autonomy of an IO is operationalised in terms of the control over resources, involvement of member states in the decision-making process and specificity of its mandate (Bauer and Ege, 2016; see also Chapter 3). An IO that has considerable resources and controls how they are raised has more autonomy to take up new issues and address issues in ways deviating from the principal's preferences than an IO that needs to have its use of resources approved by the principal. Likewise, an IO that may produce output independently of its principal has more autonomy than one in which the principal is closely involved in the production of output and that needs approval by the principal of the output. Often, the IO may produce two kinds of output: one that is produced solely by the IO bureaucracy and another which requires the approval and sometimes the active co-production of member states. The key question is then how important the outputs from the two streams are compared to each other, and how closely involved the member states are in the second stream, for example, whether they just need to approve the output or if they are involved in the decision-making process from an early stage. Furthermore, an IO with considerable degrees of freedom in its mandate, for example, to interpret the issues that fall under its portfolio, has more autonomy than those with a very specific mandate. In conclusion, the degree of IO autonomy acts as a scope condition for the influence of both the institutional worldview and policy entrepreneurs within the institutions' bureaucracies. The IMF worldview and policy entrepreneurs would be more capable of influencing institutional output 
than the OECD worldview and policy entrepreneurs, since the IMF controls its own resources and operates more independently of the member states than the OECD (Busch, 2009; Dreher and Vaubel, 2004).

Interaction with other institutions covers both the interaction among the institutions studied in the book (e.g. the OECD fulfilling secretariat functions for the G20; Hajnal, 2019) and with other institutions, especially the United Nations Framework Convention on Climate Change (UNFCCC) and the World Bank. The literature on the dyadic interaction between institutions (Oberthür and Stokke, 2011; Stokke, 2001, 2012), and on the fragmentation and coupling of institutions into institutional/regime complexes (Biermann et al., 2009a; Keohane and Victor, 2011) rests on the assumption that international institutions cannot be understood without including their relationships with other institutions. The same goes for the literature on interaction among IOs (R. Biermann, 2008; Kranke, 2020; Momani and Hibben, 2015). Interaction with other international institutions influences when and how an institution addresses climate issues. The mechanisms through which institutions are influenced by other institutions are similar to the mechanisms through which they influence other institutions, as discussed in Section 2.4. Thus, the approach adopted here is similar to the literature on dyadic interaction (Gehring and Oberthur, 2009; Oberthür and Stokke, 2011), except that I disaggregate this interaction to distinguish between the influences affecting the institutions studied here and the influences they exert influencing others.

The mechanisms include ideational change, as well as changes to incentive structures and to agenda-setting. Ideational change includes changes to the ideas within the institutions, including both cognitive and normative dimensions. As such, it may alter the ideas held by individuals within the institution (be they IO officials or member state representatives) as well as ideational environments within the institution (whose ideas are considered relevant and appropriate). The ideational environment is more institutionalised within IOs, and an IO may (to a larger degree than a forum such as the G20) be less receptive to new ideas stemming from another IO with a diverging worldview (Biermann, 2008; Momani and Hibben, 2015). In the case of cognitive ideas, this includes the provision of new knowledge or learning processes in which cognitive ideas framing fossil fuel subsidies and climate finance are changed or introduced (see also Gehring and Oberthur, 2009). Changes to the normative ideas within the institution include inter alia the institution in question accepting new normative ideas or being socialised into a norm promoted by another institution (on socialisation, see Checkel, 2005). Changes to incentive structures consists of changes to incentives facing the actors within one institution originating from another institution, including the transfer of resources, pressure to address an issue in a particular way or agreements made within one 
institution influencing the willingness to compromise in another institution (see also Zelli et al., 2020). For instance, IOs may receive more resources, or a commitment made within one institution inducing the member states of that institution to push for similar commitments within other institutions. Finally, agenda-setting concerns actions from one institution influencing the priority given to climate finance or fossil fuel subsidy reform by another institution, for example, the G20 tasking another institution to provide an analysis of climate finance or fossil fuel subsidies.

Regarding the factors shaping the alignment among the institutions, the same factors are relevant. Generally speaking, the more similar the factors shaping the output of the individual institutions, the more synergistic they will be; for example, if their worldviews are very similar and in all institutions play an important role in shaping their output, it will pull in the direction of more synergistic alignment. Interaction among institutions plays a particularly important role in encouraging the institutions to adopt similar positions. Moreover, interacting with other institutions than the ones studied here (e.g. the World Bank, the International Energy Agency) may lead to similar positions if they interact with the same set of institutions, and to divergent positions if they interact with different sets of institutions.

\subsection{Consequences of IEI Output}

The output of the institutions may have different consequences for actor behaviour, what is referred to as outcome. These consequences play out differently at the domestic and the international levels.

\subsubsection{International Consequences}

At the international level, the focus is on the influence of other intergovernmental institutions rather than on private or public-private institutions (see Betsill et al., 2015; Chan et al., 2015 for examples of literature on the interaction between intergovernmental and private and public-private institutions). The interaction covers influences on the other institutions studied here as well as on other institutions such as the UNFCCC or the World Bank. The mechanisms through which the institutions studied influence other institutions are similar to the mechanisms through which they are influenced by other institutions. Hence, the mechanisms include ideational change (cognitive and normative), changes to incentive structures (altering the incentives for actors within other institutions for particular 
actions) and agenda-setting (moving the issues up or down the agenda), as discussed in Section 2.3.

\subsubsection{Domestic Consequences}

At the domestic level, states are the main target of their output, and consequently the kind of actors that are most directly influenced by the output. Other actors, particularly companies and NGOs, may also change their behaviour as a result of the output of institutions, but most of these changes in behaviour stem from changes in state behaviour, for example, the state changing a policy due to institutional output such as norms or commitments (on the central role of the state, see Eckersley, 2004; Setzer and Nachmany, 2018). Direct influences from institutions to non-state actors are - at least regarding the topics studied here less important, and hence the focus will be on the influence on state policy. This influence includes studying the more indirect influences the institutions may have on state policy via the agency of non-state actors, for example, by making it possible for them to shame the state for not living up to international commitments.

The focus is on the individual institutions' interaction with selected countries, viz. Denmark, India, Indonesia, the United Kingdom and the United States. I draw on existing frameworks to compare different mechanisms of influences from the international to the domestic level (Dobbin et al., 2007; Knaggård et al., 2016; Marsh and Sharman, 2009; Simmons et al., 2006) to identify four causal mechanisms of influence: cognitive change, normative change, changes to incentive structures and changes to agenda-setting. Studying these influences requires a focus on their impact on policy processes and policy debates (e.g. Kingdon, 2003; Sabatier and Weible, 2014) concerning climate finance and fossil fuel subsidies respectively, including the actors within this process and the setting in which they operate. A key assumption is that domestic policy is created through policy processes, in which different sets of governmental and non-governmental actors (different ministries and agencies, politicians, interest organisations, NGOs, etc.) seek to influence policy so it reflects their preferences. These actors have to operate within the formal structures of the policy process (e.g. who has access, who is authorised to draft proposals or to reach final decisions, etc.). They also have to operate within informal, ideational structures, which shape which cognitive ideas are considered relevant and valid, and which normative ideas are considered legitimate (Bakir, 2009). These ideational structures range from fundamental ideas that are difficult to change (e.g. about the role of markets) to more specific and malleable ideas that are often rooted in the fundamental ideas (see also Jenkins-Smith et al., 2014). The 
different actors have different resources in terms of formal authority, financial resources, ability to mobilise public opinion and/or activists, and so forth.

As with the discussion of institutional output and of the causes of the output, I distinguish between cognitive and normative change, although in practice they may be difficult to disentangle. Both of these kinds of ideas may be internalised by actors as well as act as external constraints or resources for actors that do not internalise them. Importantly, new ideas that resonate with existing ideas and fundamental ideational structures (see Section 2.3) are more likely to lead to ideational change (Jenkins-Smith et al., 2014). As mentioned, these ideas can operate externally of the beliefs of policymakers, but still be something they have to take into account, or policymakers can internalise them and take them for granted (Checkel, 2005). The book focuses mainly on the institutions influencing policymakers directly, since this is the main channel of interaction for the three institutions. There is a particular focus on the officials who interact directly with the institutions, for example, finance ministry officials. Identifying the institutions' more indirect cognitive and normative influences on policy by affecting actors outside the policy process, for example, academics, think tanks or NGOs, is difficult, mainly because it is difficult to distinguish these influences from other influences on these actors. Yet the book also includes influences on the public and decision-making agenda, as discussed later in this section.

Cognitive change describes the provision of knowledge (including data) about the issue, including learning about how other actors have addressed the two issues and the lessons that can be derived from these experiences (e.g. successful cases of fossil fuel subsidy reform in other countries). Such knowledge concerns both the room for manoeuvre of actors to influence decisionmaking and how actors perceive the world. Thus, cognitive change may influence the framing and definitions used to address climate finance and fossil fuel subsidies, for example, debates regarding which definition of fossil fuel subsidies should be used to determine whether a country has subsidies (Koplow, 2018; Skovgaard, 2018). Such changes to cognitive ideas also include learning, understood as changing beliefs concerning the 'best' (generally most efficient or effective) way to achieve an objective based on experience, in this case that of other actors (Dobbin et al., 2007; Dolowitz and Marsh, 2012; Dunlop and Radaelli, 2013). Here, it is pertinent to focus on international institutions actively disseminating best practices (see Lehtonen, 2007 and Seabrooke, 2012 for the OECD and the IMF respectively) or acting as forums for peer-based learning (from both successful and unsuccessful reforms) among policymakers (Haas, 2000). 
Normative change refers to changes in policymakers' normative ideas regarding the two issues, for example, the socialisation of officials into the norm that climate finance constitutes a way of addressing the risks associated with climate change. The internalisation of norms takes place via actors (often gradually) becoming convinced about its validity, for example, through normative suasion (Checkel, 2005). Concerning normative ideas as external, actors may be bound by previous commitments to normative ideas they do not believe in (e.g. the norm of panEuropean liberalism; see Schimmelfennig, 2001) or strategically use such ideas to convince or constrain other actors (e.g. the norm of liberal internationalism; see Hurd, 2005). The spread of a normative idea within a country generally follows a pattern in which it is first internalised by a small set of actors, who are persuaded by its validity, followed by a 'cascade' in which the idea becomes established within the entire policy subsystem or society as something actors need to take into account whether they believe in it or not, and in the final stage acquires a 'taken-forgranted' quality that nobody questions (Finnemore and Sikkink, 1998). Norms and other normative ideas may be subject to contestation regarding their general appropriateness or validity, as well as regarding their application to specific situations (Wiener, 2004; Zimmermann et al., 2017).

Changes to incentive structures refers mainly to the effects of commitments (e.g. to undertake fossil fuel subsidy reform or provide climate finance) and conditionalities (e.g. cessation of IMF loans if countries do not reform fossil fuel subsidies) on the non-ideational structures facing domestic actors involved in how their country addresses fossil fuel subsidies and climate finance. It also refers to new knowledge about the credibility of other states' commitments or offers. These changes may work by influencing the power of these actors by providing them with (or withdrawing) material support or altering their power vis-à-vis other actors by providing them with powerful new international allies that seek the same objectives as them, for example, fossil fuel subsidy reform. The power of international economic institutions is well documented, particularly the influence of the IMF and World Bank programmes ${ }^{4}$ (Pop-Eleches, 2009). Changes to incentive structures may also induce actors to change their positions on policy issues by increasing the costs or benefits (for them specifically or for the country as a whole) of particular policies (Kahler, 2000). The failure to adhere to commitments to, for example, fossil fuel subsidy reform, may result in IMF loans not being delivered, or low delivery of climate finance highlighted by OECD reporting may result in reputational costs influencing international cooperation on other issues, cooperation that directly benefits the country.

Agenda-setting refers to changes to the public (e.g. the degree of attention to the issues in the media) and decision-making agendas (e.g. debates within parliament

${ }^{4}$ Often referred to as 'Structural Adjustment Programmes'. 
or the government). Reports, statements or commitments by the institutions affecting the place of fossil fuel subsidies on the public (media) and policymaking (within government, parliamentary committees, etc.) agenda constitute the most relevant agenda influences. Such influences allow actors favouring a particular policy change to initiate a debate about the policy, for example, whether the country has fossil fuel subsidies and whether they should be reformed. In this way, agendasetting may support cognitive or normative change (e.g. framing a policy as a fossil fuel subsidy), or changes to incentive structures. Likewise, changes to the position of the two issues on the agenda may be influenced by cognitive, normative or incentive-based changes.

\subsection{Summary}

The framework outlined in the preceding text is useful for exploring the institutions' handling of fossil fuel subsidies and climate finance, including the economisation in the shape of their output, and the alignment, causes and consequences of this output. The framework includes reoccurring themes, most notably cognitive, normative and incentive-based dynamics. For instance, the framework may identify whether output in the shape of commitments with a distinct normative dimension (e.g. promoting a norm) have been driven by particular normative factors and have particular normative consequences. The framework will be important for the study of economisation, since it allows one to study how economisation has taken place (including variation between institutions) and the causes and consequences of economisation in its different shapes. 